\title{
The Making of IT Teachers: Lessons Learned from Animation-enhanced Training
}

\author{
Hafizul Fahri Hanafi, Khairulanuar Samsuddin, Norhisham Mohamad Nordin, Ashardi Abas, Che Soh Said \\ Computing Department Sultan Idris Education University, Perak, Malaysia
}

\begin{abstract}
This paper discusses the roles of effective Information Technology (IT) teachers in today's challenging educational environments. The discussion begins by discerning the teaching and learning philosophy that is relevant and crucial to establishing encouraging settings for learning. Moreover, important components of effective teaching are highlighted that help nurture IT teachers' skills and proficiency. The making of effective IT teachers was addressed in a lab-based training involving 17 IT student teachers who used a host of technological tools, namely animation. Upon the completion of the training, these future IT teachers had gained the essential abilities in the specific IT domain that can improve their employability - both in private and civil sectors. This training had also honed their technical skills, making them more articulate in handling any jobs that they were assigned to do.
\end{abstract}

Index Terms- roles of effective teacher, component of teaching, IT

\section{INTRODUCTION}

$\mathrm{T}$ eaching Information Technology (IT) is mostly carried out with the use of current technologies [1], and notably the internet represents one of the most pervasive technologies used in most classrooms. In this regard, almost all Malaysian leading universities provide an eLearning infrastructure for students to access learning objects or materials.

Manuscript received 29 February 2012.

Hafizul Fahri Hanafi Author is with the Department of Computer, Faculty of Arts, Computer and Creative Industry, Universiti Pendidikan Sultan Idris (corresponding author to provide phone: 0122505531;e-mail: hafizul@fskik.upsi.edu.my).

Khairulanuar Samsuddin Co Author is with the Department of Computer, Faculty of Arts, Computer and Creative Industry, Universiti Pendidikan Sultan Idris (corresponding author to provide e-mail: khairul@fskik.upsi.edu.my).

Ashardi Abas Co Author is with the Department of Computer, Faculty of Arts, Computer and Creative Industry, Universiti Pendidikan Sultan Idris (corresponding author to provide e-mail: ashardi@fskik.upsi.edu.my).

Norhisham Mohd Nordin Co Author is with the Department of Computer, Faculty of Arts, Computer and Creative Industry, Universiti Pendidikan Sultan Idris (corresponding author to provide e-mail: norhisham@upsi.edu.my).

Che Soh Said Co Author is with the Department of Computer, Faculty of Arts, Computer and Creative Industry, Universiti Pendidikan Sultan Idris (corresponding author to provide e-mail: chesoh@fskik.upsi.edu.my).

DOI: 10.5176_2010-2283_2.1.125
To make effective use of the current technologies, knowledgeable, articulate teaching personnel should be trained to possess criteria deemed imperative in today's educational environment - that is technologically and pedagogically demanding. IT teachers should possess strong discipline content knowledge, especially in IT. This knowledge must be coupled with sound pedagogical skills, which is appropriate with the environment and discipline. Likewise, inter-personal knowledge of teachers should be groomed, allowing them the ability to forge strong relationship with students, to remain emphatic with students' needs, and to practice outstanding moral codes; and they should also inculcate intimate knowledge of the context in which they are teaching.

The diverse range of learning objects used schools, which is developed in various forms. It used to be in text-based form such as the electronic book (eBook) and .pdf [3], courseware, training, intensive assessment, tutorial, and simulation, video [4], and digital storytelling [5].

Teaching always involves communication, and communication can be carried out in many ways: SMS, MMS, email, and the latest technology typically comprising mobile android video conferencing which is supported by computer technology. No matter what technologies are used, the main activity is communicating. This is because the teacher has to disseminate some information to the receiver for students or learners. The message that is transmitted to the receiver must be understood by the receiver. The communication circle is not complete until the message receiver, through some feedback channels, informs either verbally or non-verbally, the message transmitter i.e. the teacher that the message understood has been the message sent. At the heart of effective teaching there should be an ongoing process of ensuring that what the teacher has said is what learners have understood. Some communications involve text only, audio, with supporting pictures, video, real projects and examples, and many more formats.

There are various learning modes that learners can choose. In conjunction, theory of multiple intelligences by Gardner addresses that one may have different ways of effective learning modes than the others. This relates to time, place, and kind of materials learners employ. It is suggested that the learners have to identify their own strengths, in terms of their most effective learning time, most effective learning place, and kind of material or elements that they are interested most. 
In addition, some learners perform best when they learn alone, but some would do better if they are learning in groups, and perform tasks together, some learn best while listening to music while some may expect to learn in silent. There is no right or wrong mode of learning because it depends on the learners' personality [12].

Besides, Brown, Collins, and Duguid (1989) also promote various learning styles such as self-paced learning and active learning. This idea is supported by Laurillard (1995) and Elizabeth (1997). Also, methods of learning evolve. Gradually evolved from the Behaviorist paradigm, Cognitivist paradigm, and later Constructivist paradigm, the methods of learning were incorporated with timely technologies. Primitive books and pencils, followed by better learning aids including some electronic apparatus like calculators and now learning happens in all electronic environment. From traditional method, where learners have to attend classes, meeting instructors and colleagues, and all physical learning aids and materials, today learners can learn without attending classes, and require lesser presence of instructors. Not only learning is made easy by help of electronic learning aids and materials, but also learning can happen anywhere, at anytime. The learning facilities are very ubiquitous [16], highly fostering the lifelong learning concepts.

\section{TABLE 1}

\begin{tabular}{lc}
\hline Learning methods & Rate of understanding (\%) \\
\hline Realizing real projects & 100 \\
Learning through interactive multimedia & $\mathbf{9 0}$ \\
Simulating the real situations & 90 \\
Making live performances & 90 \\
Delivering messages through speeches & 70 \\
Learning by involving in active discussions & 70 \\
Learning from live performances & 50 \\
Learning from exhibitions & 50 \\
Learning from films & 50 \\
Learning from pictures & 30 \\
Reading & 20 \\
Listening & 10
\end{tabular}

Relationships of learning methods and their rates of understanding.

Laurillard (1993) presents a conversational framework in teaching and learning. In her model, she includes learner and instructor as the main stakeholders in conversations. Learner is defined as the entity to acquire knowledge, while the instructor will disseminate knowledge to the learner. Many names associated with learner such as student, pupil, and audience; while instructor is called lecturer, teacher, or facilitator.

Further, roles of learners and instructor in this digital age are diversified. Approaches include stimuli [9], reflective practice, intrinsic feedback on action, contextualization of tasks in discourse, adaptation of tasks to discourse, adaptation of discourse to tasks, and contextualization of discourse in tasks are found suitable; these approaches are commonly implemented among learners and instructors [10]. The modes of interactions are also expanded, in which they could be content-to-learner, learner-to-instructor, learner-to-learner, or instructor-to-content [11].
Based on the discussions in the previous paragraphs, this paper outlines some components of teaching IT.

\section{COMPONENTS OF TEACHING IT}

The general components of teaching and learning are illustrated in Figure 2. The following paragraphs discuss about the components.

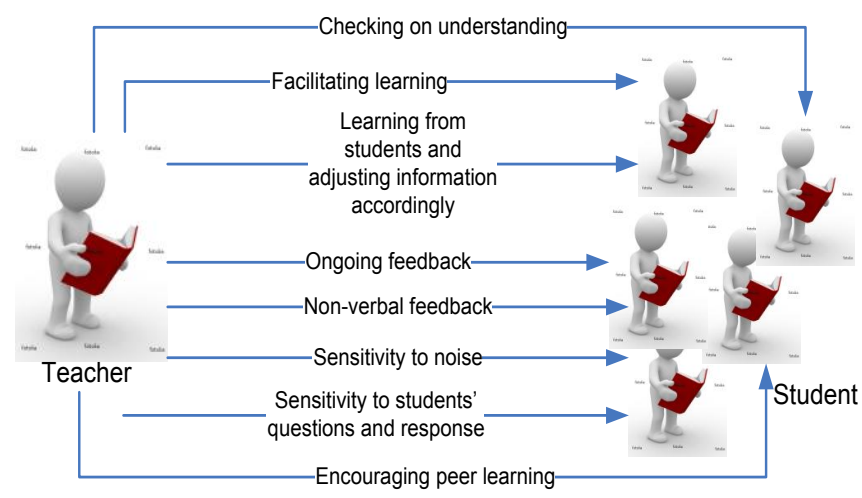

Figure 2: General components of teaching and learning

\section{Ongoing Feedback}

The teacher, based on the feedback is in a position to transmit new bits of information. On the other hand, if the feedback from the student advises the teacher that the message sent has been misunderstood the teacher has to retransmit the information. This time the message must be transmitted in such a way that the message sent equates with the message understood.

\section{Learning from Students and Adjusting Information Accordingly}

Teachers can and should also learn from students. Communication is after all a two way process. The message giver at times becomes the message receiver and vice versa. When students inform the teacher of what they have understood from her/him the effective teacher should make use of the information. With the help of this feedback information, the teacher should determine what is going right or wrong with the ways, methods, and procedures used to transfer information and knowledge.

\section{Non-verbal Feedback}

An effective teacher should also watch attentively for signs of comprehension in the facial expressions of the students. Such feedback can be seen in nods or shakes of the head, eye contact, smiles (of confidence or hesitancy), silence, etc. In order to obtain such non-verbal feedback, which is expressed not through language but by facial expressions and body language, it is imperative that the teacher should be able to see all the students. 


\section{Sensitivity to Noise}

Teachers must be perceptive and aware of the noise level in the classroom. When a teacher says something and some students start chatting as if they were asking questions from each other this should alert the teacher that some problem in understanding the message has arisen. Teachers must therefore be alert to other feedback signals such as noise and other nonverbal signals.

\section{Checking on Understanding}

To check or confirm understanding, the teacher can through either spoken or written output, obtain feedback on whether what has been taught has been understood. Communicative activities, both spoken and written should alert the teacher whether the teaching point made has been understood. Redirects are a procedure in which a teacher redirects her communication. She asks one student to report to her peer what the teacher had said. This is an informative way of determining whether students have understood the teacher's message.

\section{Sensitivity to Students' Questions and Responses}

Students will ask questions when they think they are not clear. A good teacher has to entertain the question.

\section{Peer Learning}

Incidentally, the teacher does not need to be the sole retransmitted of information. Peer learning appears to have acted as a strong motivational tool for those who felt they were lacking in some ways as compared to their peers. If, through the feedback of some students, the teacher is given to understand that there has been a communication breakdown, she can turn to students who appear to have understood, (as noted in their body language) and use them as secondary informants to retransmit the information to the student/s who appear not to have understood the teacher.

\section{Facilitating Learning}

Teachers should make use of any means to facilitate learning and boost learners' self-esteem. One important way of boosting learners' self-esteem is by linking new input to familiar or old knowledge. By linking the students' knowledge of familiar lexical or grammatical items to new knowledge or information being disseminated, an effective teacher will not only facilitate understanding but also retention of meaning of new information.

In teaching IT, a teacher should be doing more than the abovediscussed components. It involves many hands-on tasks. As discussed in the previous section, in the era of digital age, technologies take a very important role in teaching and learning. The next section elaborates the lab-based teaching practice undertaken by a group of IT students with the aim to train them to become proficient, thus ensuring their employability.

\section{EXPERIENCE}

The program that the students underwent was called iCAAPCamp; this training exposed the trainees to spend more than 12 hours daily in a computer lab. The trainees were required to be in the lab from 9am to 5am only, but they spent extra hours on their own efforts. The camp was run in two weeks comprising 14 working days. They were off on Friday. Accommodation, Food and beverages, fees, and other benefits were provided by iCAAP, which means trainees did not have to pay for the camp. Seventeen (17) selected students were approached personally to participate in the camp during the semester break. iCAAP team filtered only students with at least grade B for 'graphic and animation' course to be considered on the assumption that they are be able to perform well. The training was carried out based on a model as illustrated in Figure 1.

Figure 3 shows that there are three entities involved in the program: the university, sponsor, and industries to ensure employability [7]. The university provides prospective trainees and resources. In such this camp, each trainee must be provided with a computer (which is able to run $3 \mathrm{D}$ animation software - in this camp, MAYA was used). Besides, all equipments in a teaching lab such as projector, air-condition, video recorder, audio recorder, and the Internet are required. The university has to provide these facilities to reduce cost, because they are expensive to rent.

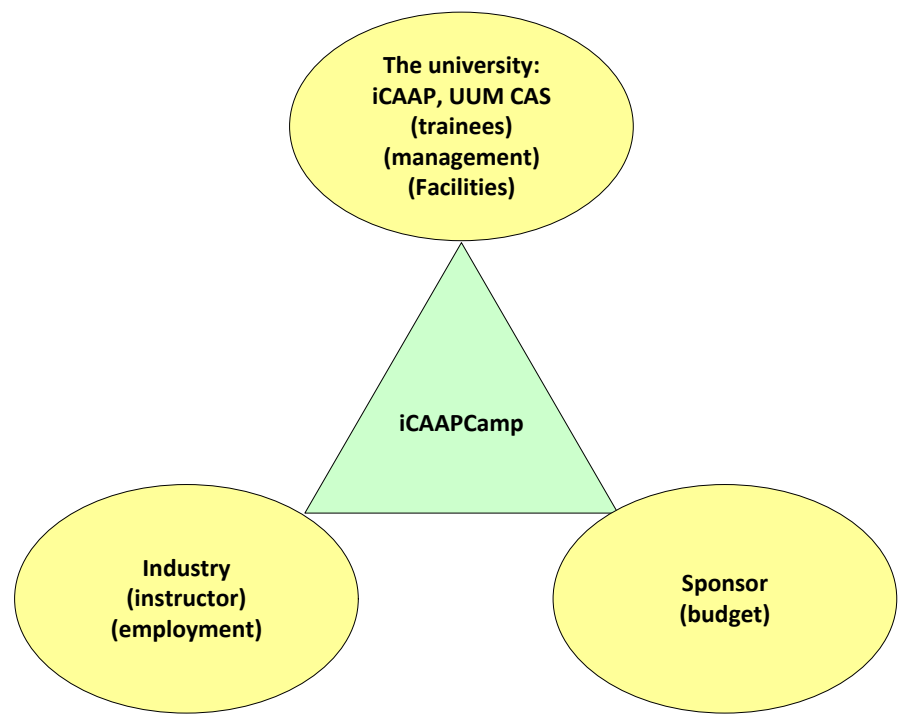

Figure 3: Training model

The other two entities are sponsor and the industry. Sponsor is a very important entity because running a camp like this requires big budget to win trainees' interest. The trainer was invited from the industry. They were very experienced, producing animated movies and TV-series. Even though expensive, the iCAAP team hired the trainers for the camp because the way they trained is very industry-oriented. Besides the big quantity for the trainers, the sponsor was also 
required for trainees' accommodation, food and beverages, certificate, materials, and management expenses.

The camp involved different parts in 3D animation process. Implicitly, the model contains components of employability as discussed by Pool and Sewell [19] i.e. career development learning, experience, degree subject knowledge, generic skills, and emotional intelligence. The following paragraphs elaborate on the implementation of the training programme.

Trainees were required to work on project basis. There were three individual projects and one group project. The individual projects comprised (1) geometrical and bedroom modeling, (2) fruits modeling, and (3) character modeling. While in group, trainees were required to do character animation. The projects evolve from less complicated to more complicated to let the trainees change their mindset and interest slowly [18]. In fourteen days, their projects were assessed by the trainer on formative basis. The trainer was able to establish personal relationship with every trainee, so that it was easy for him to approach each trainee when necessary. The rough schedule of the camp is provided in Figure 4.

\section{Activities}
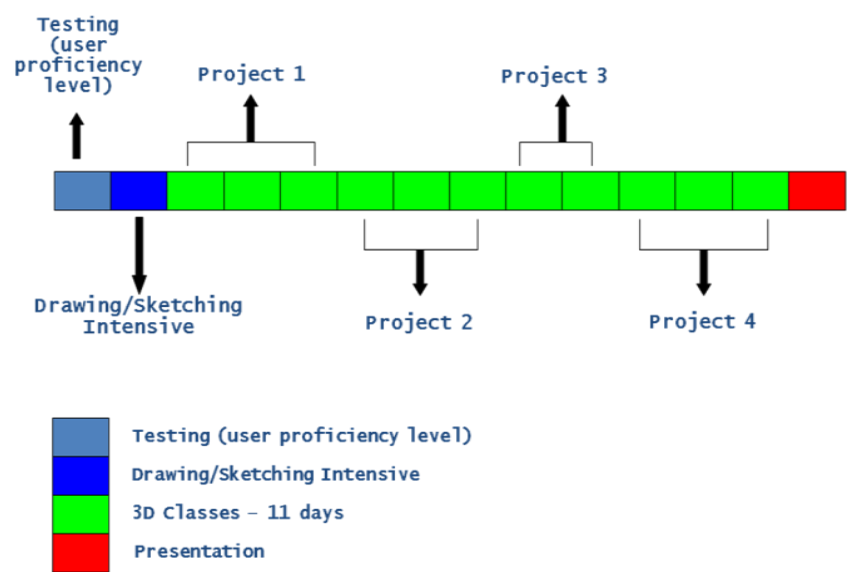

Figure 4:Camp Schedule

On the first day of meeting, the trainer briefed about the animation industry in Malaysia and in global market. Trainees were presented about the potentials of animation, and components of animation. This part was aimed at motivating the trainees besides to break the ice between the trainer and trainees. Also, the trainer made use of this session to know the level of skills each trainee posses. In detail, the first day consisted of these activities: Ice-breaking, briefing on animation industry, software for animation industry, 3D animation workflow/pipeline, and briefing on tools for learning animation, and question and answer session.
On day 2, trainees went through intensive drawing/sketching exercises. The training started off with basic lines and shapes sketches followed by basic geometry, organic shapes, and characters sketching such as human hands, face and figures.

Basic geometry modeling project aimed at developing trainees' skills in modeling basic geometry and primitive objects. All detailing such as lighting, texturing and rendering were emphasized [19]. This is the basic step in 3D modeling. The trainees were assigned to develop a fully furnished bed room using Geometry Modeling technique.

Having successful modeled the basic shapes in Project 1, trainees were asked to model more complex objects in Project 2. In organic modeling, the trainees were trained to model the shapes of organic objects such as fruits and vegetables. The project was more complicated because it contains many complex shapes. Trainees were required to imitate pictures selected from the Internet.

Character modeling requires participants to model any characters such as animals, human being, or characters out of their imaginations and creativities. The artifacts from sketches on day 2 were selected for character modeling.

Animating the character was done in groups. Each group of maximum 4 trainees was given a 3D file containing a human character model. The days left were not enough for trainees to model the character themselves, because it is complicated as discussed by [19]. They were required to add physical parts and animating the character. Assessments were based on creativity and accuracy of using the lip sync.

Each trainee was asked to present their Projects 1, 2, and 3 individually. Project 4 was presented in groups because it was a group project. Three juries were present on this presentation; two of them are multimedia lecturers of College of Arts and Sciences. The third jury was a key player in multimedia and animation industry in Malaysia. Besides the juries, other key players in the industries were invited to attend the presentation session for eying the showcase.

The outcome of iCAAPCamp is outstanding. All trainees were selected during the final presentation to do their industrial training in animation companies. Out of 17, one is recruited in the USA, two in Bangkok, and the rest are with Malaysianbased international companies. All expenses for practical training including air-fares, visa, and daily allowances are sponsored. With these encouragements, these trainees are expected to further be employed by animation companies either locally or internationally. Moreover, the companies which employed the trainees for industrial training were interested to employ them as permanent staff after the industrial training period. 


\section{DISCUSSIONS}

The general components of teaching and learning as illustrated in Figure 2 were implemented in the iCAAPCamp. Besides, the approach was also added with help of technology components. Some examples of the technology components are described in the following paragraphs.

The communication was made easy with help of eLearning infrastructure. With the technology, students could communicate among each other and with the teacher at any time when necessary. Also, electronics references such as video, courseware, and eBooks were utilized. The Internet was ready for students to access for additional resources such as online tutorials and demonstrations. The roles of the teacher for this are as a motivator and facilitator. All learning modes listed in Table 1 were implemented in iCAAPCamp.

\section{CONCLUSION}

The general components of teaching and learning as illustrated in Figure 2 were implemented in the iCAAPCamp. Moreover, the approach adopted was enabled with the help of the relevant technology components. The communication was made easy with the help of eLearning infrastructure. With the technology, students could communicate with each other and with the teacher when necessary [21]. Also, electronics references such as video, courseware, and eBooks were utilized. The Internet was ready for students to access for additional resources such as online tutorials and demonstrations. The roles of the teacher in this situation were as a motivator and a facilitator. All learning modes listed in Table 1 were implemented in iCAAPCamp.

\section{REFERENCES}

[1] Becker, H. J. (1999). Internet use by teachers: Conditions of professional use and teacher-directed student use, [WWW].Center for Research on Information Technology and Organizations. The University of California, Irvine, and the University of Minnesota.

[2] Ward, D. R., \& Tiessen, E. L. (1999). Kosmeo: A second generation tool for collaborative project-based learning. In Proceedings of the World Conference of Educational Multimedia and Hypermedia (ED-MEDIA'99), Seattle, WA.

[3] Norshuhada, S. \& Landoni, M. (2003). Children's E-Book Technology: Devices, Books and Book Builder, International Journal of Information Technology in Childhood Education Annual, AACE, USA, 105-138.

[4] Chapman, N. \& Chapman, J. (2002). Digital Media Tools. John Wiley \& Sons, Ltd. England

[5] Freidus, N. \& Hlubinka, M. (2002). Digital Storytelling for Reflective Practice in Communities of Learners. SIGGROUP Bulletin. August 2002. 23 (2). 24-26.

[6] Pool, L.D. \& Sewell, P. (2007). The key to employability: Developing a practical model of graduate employability. Education + Training. 49(4). 277-299.

[7] Foster, D. (2006). Reflection of a careers advisor. Journal of The Association of Graduate Careers Advisory Services. Nos 117. Summer. 5-6.

[8] NITC Malaysia. (2009). Malaysian Information, Communications and Multimedia Services 886. Retrieved from http://www.ntic.org.my/index.cfm?\&menuid=5 on $1^{\text {st }}$ December 2009.

[9] Aufenanger, S. (2005). Stimuli, not set answers. Televizion. 18/2005 E. 53-55.

[10] Lee, N. (2006). Design as a learning cycle: A conversational experience. Studies in learning, evaluation innovation, and development. 3(2). 12-22.

[11] Tuovinen, J. (2001). Finnish virtual (online) collaborative university - A model for Australia. In Proceedings of ASCILITE'01: Meeting at the Crossroads. Melbourne, Australia.

[12] Gardner, H. (1993). Multiple Intelligences: The Theory in Practice, NY. Basic book

[12] Brown, J.S., Collins, A. \& Duguid, S. (1989) Situated cognition and the culture of learning. Educational Researcher, 18(1), 3242

[13] Laurillard, D. (1995). Rethinking University: Teaching in The Digital Age, retrieved from https://www.educause.edu/ir/library/pdf/ffp0205s.pdf on 2 April 2007

[14] Elizabeth, L. H. (1997). A Learning Model That Develops Students' Active Learning and Reflective Practices. Frontiers in Education Conference, USA

[15] Greenfield, A. (2006). Everyware: The dawning age of ubiquitous computing. New Riders. USA

[16] Laurillard, D. (1993). Rethinking university teaching: A framework for the effective use of educational technology. London: Routledge.

[17] Bandura, A. (1995). Exercise of personal and collective efficacy in changing societies. In Bandura, A. (Ed). Self-Efficacy in Changing Societies. Cambridge University Press, Cambridge. 145.

[18] Pool, L.D. \& Sewell, P. (2007). The key to employability: Developing a practical model of graduate employability. Education + Training. 49(4). 277-299.

[19] Birn, J. (2006). Digital Lighting and Rendering (2 ${ }^{\text {nd }}$ Edition). New Riders. USA.

[20] Jain, E., Sheikh, Y., \& Hodgins, J. (2009). Leveraging the talent of hand animators to create three-dimensional animation. In Proceedings of ACM SIGGRAPH Symposium on Computer Animation (2009). 93-102. ACM.

[21] Hafizul Fahri Hanafi,Nazre Abdul Rashid, Harnani Mat Zin. Internet Technology for Teaching and Learning at Sultan Idris Education University: A Survey for Blog, Wikis and RSS In Proceedings of National Convention 2008,22-25

Hafizul Fahri was born in Petaling Jaya Selangor, Malaysia in 1980. He received BSc Degree (Software Engineering) and Msc Degree (Real Time Programming) from UTM (University of Technology Malaysia), in 2002 and 2003 respectively. In 2006, he joined the Department of Computer Science, Sultan Idris Computing Department, as a Computer Science Lecturer. He was also a reviewer of some conferences and Journals. He also currently is doing some research on Computer Software in Education, Mobile Learning and Artificial Intelligent. 